Çukurova Üniversitesi Mühendislik Fakültesi Dergisi, 36(2), ss. 359-368, Haziran 2021

Cukurova University Journal of the Faculty of Engineering, 36(2), pp. 359-368, June 2021

\title{
Üç Farklı İstatistiksel Dağılım Yöntemleri Kullanarak Rüzgar Enerjisi Potansiyelinin Tahmin Edilmesi
}

\author{
Bülent YANIKTEPE ${ }^{1}$, Osman KARA*1 \\ ${ }^{1}$ Osmaniye Korkut Ata Üniversitesi, Mühendislik Fakültesi, Enerji Sistemleri Mühendisliği \\ Bölümü, Osmaniye
}

Geliş tarihi: 24.03.2021

Kabul tarihi: 30.06 .2021

$\ddot{\mathbf{O} z}$

Son yıllarda enerjide dışa bağımlılı̆̆ı azaltmada, temiz, güvenilir, tükenmeyen ve sürdürülebilir avantajları bakımından rüzgar enerjisi ülkemizde önemli bir rol oynamaktadır. Bu çalışmada Grafik Yöntemi (Graphical Method_GM), En Yüksek Olabilirlik Yöntemi (The maximum likelihood method_MLM) ve Değiştirilmiş En Yüksek Olabilirlik Yöntemi (The modixed maximum likelihood method_MMLM) kullanılmıştır. Osmaniye Korkut Ata Üniversitesi Mühendislik Fakültesi çatısında kurulu ölçüm cihazı kullanılarak rüzgar hızı karakteristiği ve rüzgar enerjisi potansiyeli tahmini yapılmıştır. GM, MLM ve MMLM yöntemleri sonuçlarına göre yıllık belirlilik katsayısı $\left(\mathrm{R}^{2}\right)$ değerleri sırasıyla $0,9409,0,8617$ ve 0,8509 elde edilmiştir. Sonuç olarak, ölçüm yapılan yılın verilerine ve $\mathrm{R}^{2}=0,9409$ sonucuna göre GM yöntemi diğer yöntemlerden daha iyi sonuç vermiştir.

Anahtar Kelimeler: Rüzgar enerjisi, Weilbull dağılımı, Osmaniye, İstatistiksel analiz

\section{Estimating Wind Energy Potential Using Three Different Statistical Distribution Methods}

\begin{abstract}
In recent years, wind energy plays an important role in our country in reducing foreign dependency in energy and in terms of its clean, reliable, inexhaustible and sustainable advantages. In this study, Graphical Method_GM, The Maximum Likelihood Method_MLM and The Modixed Maximum Likelihood Method_MMLM were used. Wind speed characteristic and wind energy potential were estimated using the measuring device installed on the roof of Osmaniye Korkut Ata University Engineering Faculty. According to the results of GM, MLM and MMLM methods, the annual coefficient of determination $\left(\mathrm{R}^{2}\right)$ values were $0.9409,0.8617$ and 0.8509 , respectively. As a result, GM method gave better results than other methods according to the data of the year of measurement and the result of $\mathrm{R}^{2}=0.9409$.
\end{abstract}

Keywords: Wind energy, Weilbull distribution, Osmaniye, Statistical analysis

*Sorumlu yazar (Corresponding author): Osman KARA, osmankara@osmaniye.edu.tr 


\section{GíRiș}

Dünyada ve Türkiye'de enerji ihtiyacı, gelişen teknolojilerin günlük hayatımızda hızla yer almasından dolayı, artmaktadır. Ayrıca, ülkelerde şehirleşmenin yaygınlaşması ve ekonomik rekabet enerji ihtiyacına olan talebin daha fazla artmasına neden olmaktadır. Bu taleplerin karşılanmasında, mevcut konvansiyonel yakitların kullanılması ve bu tür kaynakların zamanla azalması ve hatta tükenecek olması, günümüzde pek çok ülke tarafından enerji problemlerinin çözümlenmesine yönelik çalışmaların arttığı görülmektedir. Enerji ile ilgili çalışmalarda, enerji verimliliği ve tasarrufları öncelik olmasına rağmen, yenilenebilir enerji kaynakları ile ilgili çalışmalarda oldukça önemli bir oranda artış göstermektedir. Çevreci, temiz, tükenmeyen ve dışa bağımlılıkta önemli bir aktör olarak yenilenebilir enerji kaynakları oldukça önem kazanmıştır. Yenilenebilir enerji kaynakları içerisinden en önemli kaynaklardan bir tanesi rüzgar enerjisidir. Son yıllarda rüzgar enerjisinin gelişimi ve teknolojisi ile ilgili hem ülkemizde hem de diş ülkelerde yürütülen akademik çalışmalar artmaktadır.

Rüzgar enerjisi potansiyeli ile rüzgar enerjisinin dünyada ve ülkemizdeki durumu Şenel ve Koç [1] tarafından analiz edilmiştir. $\mathrm{Bu}$ çalışmada ülkemizde rüzgar enerji potansiyeli ve rüzgar enerji santralleriyle ilgili bilgiler sunulmuştur. Ülkemizin rüzgar enerjisi kurulu gücü, diğer ülkeleri ile kıyaslanıp, yıllar içerisindeki yenilikler incelenmiştir. Ayrıca, rüzgar enerjisinin yenilenebilir enerji kaynakları içerisindeki oranları verilip, bu oranların daha da arttırılması ile ilgili öneriler verilmiştir.

Özdamar [2], yüksek ve düşük rüzgar enerji potansiyeline sahip bölgelerde, rüzgar enerjisinden elektrik enerjisinin sağlanmasında, farklı anma gücü özelliklerine sahip, 10 adet rüzgar türbini kullanarak, bu türbinleri birbiri arasında karşılaştırılmış ve sonuçları yorumlamıştır. Senkron jeneratörlü rüzgar türbinleri, düşük kapasiteli rüzgar enerjili alanlarda tercih edilirken, asenkron tip jeneratörler, yüksek rüzgar enerjisi potansiyelli alanlarda daha etkili olduğu belirlenmiş ve ayrıca, $600 \mathrm{~kW}$ nominal güce sahip rüzgar türbinlerinin, orta düzeydeki $(10 \mathrm{~m}$ yüksekliği simgeleyen) rüzgar enerjisi potansiyeli için, 1250-1300 kW nominal güçlü rüzgar türbinlerinin ise yüksek düzeydeki $(70 \mathrm{~m}$ yüksekliği simgeleyen) potansiyeller açısından önerilmiştir.

Özşahin ve Kaymaz [3], Hatay bölgesindeki rüzgar enerjisi santrallerin yapım yerlerini coğrafi faktörleri ve metotları kullanarak incelemişlerdir.

Çalışma sonuçlarını, arazi çalışmaları ile yerinde kontrol edip, bölgenin rüzgar enerjisi santralleri yapımında \%45,19; orta ve \%25,64; iyi hassasiyette bir bölge olduğu belirlenmiştir. Ayrıca, sıra dışı, zayıf ve mükemmel arazilerin ise bölgedeki rüzgar enerjisi santral yapımı yerleri içerisindeki payının yaklaşık $\% 1$ olduğu sonucuna varılmıştır.

Bilgili ve arkadaşları [4], Weibull ve Rayleigh dağılım fonksiyonları ile WAsP (Wind Atlas Analysis and Application Program) paket programı kullanıp, Türkiye'nin güney, güneybatı ve batı kıyısında yer alan bazı bölgelerin rüzgar enerjisi potansiyelini inceleyip, istatistiksel olarak analizlerini yapmışlardır. Ege, Marmara ve Doğu Akdeniz Bölgesinin bazı kısımlarında rüzgar santrali kurulmasına uygun bölgeler olduğu sonucuna varmışlardır. Ayrıca, ele alınan bölgeler içerisinde rüzgar gücü potansiyeli en yüksek bölgeler sırasıyla Gökçeada $\left(526 \mathrm{~W} / \mathrm{m}^{2}\right)$, Gelibolu $\left(410 \mathrm{~W} / \mathrm{m}^{2}\right)$ ve Belen $\left(387 \mathrm{~W} / \mathrm{m}^{2}\right)$ olduğu görülmüştür.

Yıldırım ve arkadaşları [5], 2008-2009 yılları arasındaki Niğde ilinde 10 metre yükseklikte ölçülen meteoroloji verilerini, Weibull dağılımı fonksiyonun moment metodu ve enerji eğilim faktörü parametreleri kullanarak, bölgenin rüzgar enerjisi potansiyeli istatistiksel olarak incelemişlerdir. Çalışmalarında, moment metodunun, hata analizlerine (Belirleme katsayısı ve ortalama hata kareleri toplamının karekökü) göre değerlendirilmiş ve bu metottun bu ölçüm verilerine göre daha iyi sonuç verdiğini görmüşlerdir. Ayrıca, bölgenin aylık, mevsimsel ve yıllık olarak rüzgar enerjisi potansiyelini elde etmişlerdir. 
Gülersoy ve Çetin [6], 2008-2009 y1llarına ait ölçülen rüzgar hız verilerini kullanarak, Menemen bölgesinin Weibull ve Rayleigh dağılım fonksiyonunu araştırmışlardır. Weibull dağılım modeli ile elde edilen değerlerin, Rayleigh modelinden elde edilen değerlerden daha iyi sonuçlar verdiğini göstermişlerdir. Hesaplamalarında, Weibull dağılımı için şekil parametresi, 1,838-1,869 ve ölçek parametresinin, 5,629-5,898 aralığında değiştiği bulunmuştur.

Bir bölgenin rüzgar enerjisi potansiyeli belirlenmesinde rüzgar türbinlerinin hub yüksekliği referans (rüzgar hızı ölçümü veya tahmini) alınmaktadır. Dikmen ve Örgen [7], Burdur-Ağlasun bölgesinde $2 \mathrm{~m}$ yükseklikte kurulan, Ocak-Aralık 2013 dönemleri arasında rüzgar hızını ölçüp, rüzgar türbinin farklı hub yüksekliklerindeki rüzgar hızını tahmin etmişler ve bölgenin en uygun rüzgar türbini $(65 \mathrm{~m}$ hub yüksekliğinde) önermişlerdir. Çalışmalarında, ayrıca bölgeden elde edilebilecek enerji 281560$154039 \mathrm{kWh}$ arasında olduğu hesaplanmıştır.

Akkaya ve arkadaşları [8] Mersin-Mut bölgesinde bir evin 1sıtma ve elektrik ihtiyacının karşılanması için rüzgar hızı verilerini incelemişlerdir. Rüzgar enerjisi potansiyelinin tahmini için 12 ay boyunca alınan verilerle yapay bir sinir ağı modeli oluşturulmuş ve rüzgar verilerinin sürekliliğini araştırmak için rüzgar verileri sınıflandırılmıştır. Bölge için yapılan çalışmada rüzgarın devamlılığının kullanıma uygun olduğu sonucuna varılmıştır. Rüzgar verileri için çok katmanlı sensor algoritması için MAE ve RMSE değerleri sırasıyla 0,4056 ve 0,5403 hesaplanmış, ayrıca bölgenin mevcut ortalama rüzgar hızı $80 \mathrm{~m}$ rakım için WAsP yazılımı ile belirlemiştir.

Kurban ve arkadaşları [9] Anadolu Üniversitesi İki Eylül Kampusunda kurulan ölçüm istasyonundan belirli bir yılın dört aylık peryodundan $15 \mathrm{sn}$ ölçüm verilerini kullanılarak istatistiksel dağılım fonksiyonları (Weibull ve Rayleigh) ile bölgenin rüzgar enerjisi potansiyeli analiz etmişlerdir. Ayrıca çalışmalarında, aylık ortalama güç yoğunlukları açısından incelendiğinde ortalama aylık güç yoğunluğunun değişiminin çok fazla olmadığ1, yıl içerisindeki güç yoğunluğunun değişiminde en yüksek değerin Ağustos ayında olurken, en düşük değerin Ekim ayında gerçekleştiği sonucuna varılmıştır.

Bir bölgede rüzgar enerjisinden elektrik enerjisinin elde edilmesi için rüzgar türbinlerinin kurulmadan önce bölgenin rüzgar hızının ölçülmesi, rüzgar hızının karakteristiğinin ve potansiyelinin belirlenmesi büyük bir öneme sahiptir. Rüzgarın hızı yerden yükseklikle artmakta, güç ise rüzgar hızının küpüyle orantılı olarak değişmektedir. Bu çalışmada Osmaniye Korkut Ata Üniversitesi, Mühendislik Fakültesinde ölçümü yapılan rüzgar hızı ile kampüsün rüzgar anemometresi ölçümüyle rüzgar enerjisi potansiyeli üç farklı istatistiksel yöntem kullanılarak belirlenmiştir. Yöntemlerin performans analizi yapılarak karşılaştırılmış ve bu ölçüm verileri ile kampüs yerleşkesi için en iyi yöntem bulunmuştur.

\section{TÜRKIYY'DE VE OSMANIYYE'DE KURULU RÜZGAR GÜCÜ}

Türkiye'de 2006 yılında, belirli bir yer yüksekliği $(50 \mathrm{~m})$ ve rüzgar hızına $(7,5 \mathrm{~m} / \mathrm{s}$ üzeri) sahip bölgeler için kilometre başına rüzgar santralleri (5 MW) kurulabileceği kabulüyle, bazı modeller (orta-ölçekli sayısal hava tahmin modeli ve mikroölçekli rüzgar akış modeli) kullanılarak Rüzgar Enerjisi Potansiyel Atlası oluşturulmuştur. Bu kabuller ile Türkiye'nin rüzgar enerjisi potansiyeli yaklaşık 48,000 MW olarak belirlenmiștir. Bu rüzgar enerjisi potansiyeli için gerekli olan alan, Türkiye'nin yüz ölçümünün \%1,30'luk bir kısmidir [10].

Türkiye Rüzgar Enerjisi Birliği, Temmuz 2020 [11] raporuna göre Rüzgar Enerjisi Santrallerin (RES) İllere göre, Çizelge 1'de Türkiye'de İşletmedeki RES'lerin, Çizelge 2'de Türkiye'de İnşa Halindeki RES'lerin, Çizelge 3'de Türkiye'de Lisanslı RES'lerin, Çizelge 4'de Türkiye'de Ön Lisanslı RES'lerin İllere göre Dağılımları verilmiştir. Rapora göre, Türkiye'de işletmedeki RES'lerin toplam kurulu gücü, $8288 \mathrm{MW}$; İnşaa Halindeki RES'lerin kurulu gücü 2451,05 MW; Lisansl1 RES'ler 688,25 MW iken Ön Lisanslı RES'lerin kurulum kapasitesi 4536,60 MW'tır. Bu 
rapor kapsamında incelenen Osmaniye İlinin kurulu güç kapasitesi 265,30 MW değerindedir. Osmaniye ilinde, Gökçedağ, 135 MW; Hasanbeyli, $50 \mathrm{MW}$ ve Sartepe-Demirciler, 80,3 MW kapasiteye sahip rüzgar santralleri bulunmaktadır.

İllere göre en fazla kurulu güç kapasitesi sırasıyla İzmir, Balıkesir, Manisa ve Çanakkale ileri olduğu görülmektedir. Ayrıca, ülkemizde, Enerji ve Tabii Kaynaklar Bakanlı̆̆ı, Yenilenebilir Enerji Genel
Müdürlüğü, Meteoroloji Genel Müdürlüğü, Türkiye Bilimsel ve Teknolojik Araştırma Kurumu işbirliğinde Milli tabanlı Rüzgar Gücü İzleme ve Tahmin Merkezi projesi 2014 yılında tamamlanmıştır. $\mathrm{Bu}$ proje ile rüzgar enerji santralleri tek bir merkezden izlenip, rüzgar gücü tahmini daha doğru bir şekilde yapılması ile sektöre daha etkin bir katk1 sunulması sağlanmaktadır $[12,13]$.

Çizelge 1. Türkiye'de işletmedeki RES'lerin illere göre dağılımı [11]

\begin{tabular}{|l|c|c|l|c|c|}
\hline İller & $\begin{array}{c}\text { Kurulu güç } \\
\text { kapasitesi } \\
(\mathbf{M W})\end{array}$ & $\begin{array}{c}\text { Kurulu güç } \\
\text { yüzdesi (\%) }\end{array}$ & \multicolumn{1}{|c|}{ Iller } & $\begin{array}{c}\text { Kurulu güç } \\
\text { kapasitesi } \\
\text { (MW) }\end{array}$ & $\begin{array}{c}\text { Kurulu güç } \\
\text { yüzdesi (\%) }\end{array}$ \\
\hline İzmir & 1619,60 & 19,54 & Amasya & 141,10 & 1,70 \\
\hline Balıkesir & 1166,05 & 14,07 & Tokat & 140,70 & 1,70 \\
\hline Manisa & 716,75 & 8,65 & Yalova & 130,85 & 1,58 \\
\hline Çanakkale & 617,85 & 7,45 & Bursa & 130,80 & 1,58 \\
\hline Hatay & 362,05 & 4,37 & Kahramanmaraş & 86,40 & 1,04 \\
\hline Afyon & 356,45 & 4,30 & Edirne & 85,60 & 1,03 \\
\hline İstanbul & 295,60 & 3,57 & Denizli & 74,80 & 0,90 \\
\hline Kayseri & 274,35 & 3,31 & Gaziantep & 65,55 & 0,79 \\
\hline Osmaniye & 265,30 & 3,20 & Isparta & 61,20 & 0,74 \\
\hline Mersin & 221,55 & 2,67 & Samsun & 56,00 & 0,68 \\
\hline Aydın & 216,20 & 2,61 & Uşak & 44,00 & 0,65 \\
\hline Kırklareli & 199,60 & 2,41 & Bilecik & 27,50 & 0,48 \\
\hline Muğla & 197,25 & 2,38 & Adıaman & 11,70 & 0,33 \\
\hline Tekirdağ & 174,20 & 2,10 & Malatya & 10,20 & 0,14 \\
\hline Kırşehir & 168,00 & 2,03 & Kocaeli & 8288,00 & 0,12 \\
\hline Konya & 165,50 & 2,00 & & & 100,00 \\
\hline Sivas & 155,30 & 1,87 & TOPLAM & & \\
\hline
\end{tabular}

Çizelge 2. Türkiye'de inşa halindeki RES'lerin illere göre dağılımı [11]

\begin{tabular}{|l|c|c|l|c|c|}
\hline İller & $\begin{array}{c}\text { Kurulu güç } \\
\text { kapasitesi } \\
(\mathbf{M W})\end{array}$ & $\begin{array}{c}\text { Kurulu güç } \\
\text { yüzdesi (\%) }\end{array}$ & \multicolumn{1}{|c|}{ Iller } & $\begin{array}{c}\text { Kurulu güç } \\
\text { kapasitesi } \\
\text { (MW) }\end{array}$ & $\begin{array}{c}\text { Kurulu güç } \\
\text { yüzdesi (\%) }\end{array}$ \\
\hline İstanbul & 302,30 & 11,33 & Konya & 54,00 & 2,20 \\
\hline Sakarya & 272,30 & 11,52 & Van & 53,20 & 2,17 \\
\hline Kırklareli & 278,40 & 11,36 & Yalova & 53,20 & 2,17 \\
\hline Çanakkale & 272,00 & 11,10 & Eskişehir & 52,80 & 2,15 \\
\hline Balıkesir & 254,20 & 10,37 & Kirkkale & 43,20 & 1,76 \\
\hline İzmir & 249,85 & 10,19 & Kahramanmaraş & 35,10 & 1,43 \\
\hline Aydın & 149,40 & 6,10 & Hatay & 28,80 & 1,18 \\
\hline Bursa & 140,80 & 5,74 & Edirne & 11,40 & 0,47 \\
\hline Bilecik & 124,50 & 5,08 & Manisa & 10,80 & 0,44 \\
\hline Kocaeli & 54,80 & 2,24 & TOPLAM & 2451,05 & 100,00 \\
\hline
\end{tabular}


Çizelge 3. Türkiye'de lisanslı RES'lerin illere göre dağılımı [11]

\begin{tabular}{|l|c|c|l|c|c|}
\hline İler & $\begin{array}{c}\text { Kurulu güç } \\
\text { kapasitesi } \\
(\mathbf{M W})\end{array}$ & $\begin{array}{c}\text { Kurulu güç } \\
\text { yüzdesi (\%) }\end{array}$ & \multicolumn{1}{|c|}{ iller } & $\begin{array}{c}\text { Kurulu güç } \\
\text { kapasitesi } \\
\text { (MW) }\end{array}$ & $\begin{array}{c}\text { Kurulu güç } \\
\text { yüzdesi (\%) }\end{array}$ \\
\hline Bursa & 129,50 & 18,82 & Tekirdağ & 14,00 & 2,03 \\
\hline Yalova & 112,00 & 16,27 & Ordu & 12,00 & 1,74 \\
\hline Konya & 102,30 & 14,86 & Manisa & 10,20 & 1,48 \\
\hline İstanbul & 71,00 & 10,32 & Çanakkale & 10,00 & 1,45 \\
\hline Muğla & 64,00 & 9,30 & Edirne & 6,00 & 0,87 \\
\hline Hatay & 47,00 & 6,83 & Sinop & 6,00 & 0,87 \\
\hline Trabzon & 40,00 & 5,81 & İzmir & 2,25 & 0,33 \\
\hline Mersin & 32,00 & 4,65 & & & \\
\hline Kirklareli & 30,00 & 4,36 & & & \\
\hline & & & TOPLAM & 688,25 & 100,00 \\
\hline
\end{tabular}

Çizelge 4. Türkiye' de ön lisanslı RES'lerin illere göre dağılımı [11]

\begin{tabular}{|c|c|c|c|c|c|}
\hline İller & $\begin{array}{c}\text { Kurulu güç } \\
\text { kapasitesi } \\
\text { (MW) }\end{array}$ & $\begin{array}{l}\text { Kurulu güç } \\
\text { yüzdesi }(\%)\end{array}$ & İller & $\begin{array}{c}\text { Kurulu güç } \\
\text { kapasitesi } \\
(\mathrm{MW})\end{array}$ & $\begin{array}{l}\text { Kurulu güç } \\
\text { yüzdesi (\%) }\end{array}$ \\
\hline Kirklareli & 482,0 & 10,62 & Kütahya & 50,40 & 1,11 \\
\hline Edirne & 335,40 & 7,39 & Erzincan & 50,30 & 1,11 \\
\hline Sivas & 330,00 & 7,27 & Erzurum & 50,00 & 1,10 \\
\hline İstanbul & 290,00 & 6,39 & Eskişehir & 50,00 & 1,10 \\
\hline Çanakkale & 270,70 & 5,97 & Muğla & 50,00 & 1,10 \\
\hline Balıkesir & 236,70 & 5,22 & Bingöl & 49,50 & 1,09 \\
\hline Mersin & 156,60 & 3,45 & Samsun & 49,00 & 1,08 \\
\hline Karaman & 136,20 & 3,00 & Sinop & 47,00 & 1,04 \\
\hline Adana & 115,40 & 2,54 & Uşak & 47,00 & 0,97 \\
\hline Yalova & 112,00 & 2,47 & Kırıkkale & 44,00 & 0,94 \\
\hline Bursa & 110,80 & 2,44 & Adiyaman & 42,50 & 0,88 \\
\hline Antalya & 101,50 & 2,24 & Bitlis & 40,00 & 0,88 \\
\hline Malatya & 82,00 & 1,81 & Elazı ̆̆ & 40,00 & 0,88 \\
\hline Kayseri & 80,00 & 1,76 & Giresun & 40,00 & 0,88 \\
\hline Kocaeli & 70,00 & 1,54 & Kahramanmaraş & 40,00 & 0,88 \\
\hline Çorum & 65,00 & 1,43 & Kilis & 40,00 & 0,88 \\
\hline Isparta & 63,00 & 1,39 & Tokat & 40,00 & 0,88 \\
\hline Tekirdağ & 60,90 & 1,34 & Afyonkarahisar & 30,00 & 0,66 \\
\hline Hatay & 60,00 & 1,32 & Karabük & 30,00 & 0,66 \\
\hline Kırşehir & 60,00 & 1,32 & Manisa & 30,00 & 0,66 \\
\hline Mardin & 60,00 & 1,32 & Sakarya & 30,00 & 0,66 \\
\hline Çankırı & 54,60 & 1,20 & Ankara & 20,00 & 0,44 \\
\hline Konya & 54,00 & 1,19 & Kars & 20,00 & 0,44 \\
\hline İzmir & 52,00 & 1,15 & Amasya & 11,00 & 0,24 \\
\hline Yozgat & 52,00 & 1,15 & Budur & 3,00 & 0,07 \\
\hline A ğr1 & 51,30 & 1,13 & & & \\
\hline \multirow[t]{2}{*}{ Ordu } & 50,80 & 1,12 & & & \\
\hline & & & TOPLAM & 4536,60 & 100,00 \\
\hline
\end{tabular}


Şekil 1'de Osmaniye iline ait RES haritaları gösterilmiştir. Osmaniye iline ait meteoroloji verilere göre, minimum rüzgar hızı $(\mathrm{m} / \mathrm{s}) 1,78$ olur iken maksimum rüzgar hızı (m/s) 7,92'dir [14].
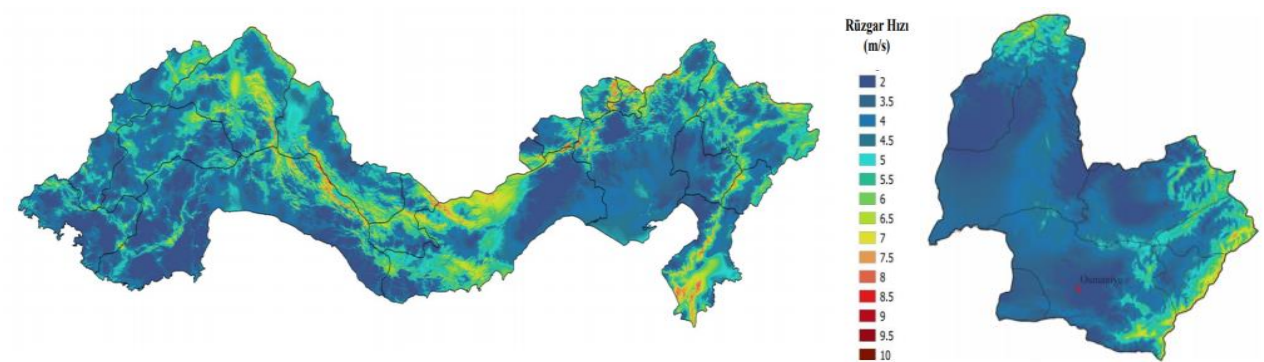

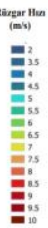

Şekil 1. Akdeniz Bölgesi ve Osmaniye ilinin yıllık ortalama rüzgar hızı dağılımı [14]

\section{RÜZGAR HIZI ÖLÇÜMÜ}

Bu çalışmada Osmaniye Korkut Ata Üniversitesi Mühendislik Fakültesi binasında yaklaşık $20 \mathrm{~m}$ yükseklikte anemometre ile ölçüm yapılmıştır. Bu ölçüm istasyonundan Ocak-Aralık 2013 dönemlerinde 10'ar dakikalık kaydedilen ölçüm değerleri kullanılmıştır. Çizelge 5'de ölçümü yapılan rüzgar hızı değerleri verilmiştir. Çizelge 5'teki ölçüm değerlerinin toplamı yıl içerisinde 52560 değer olması gerekirken burada 49171 ölçüm alınmış olup, 3389 ölçüm değeri alınamamıştır.

Çizelge 5. Ölçülen rüzgar hız değerleri

\begin{tabular}{|c|c|c|c|c|c|}
\hline $\mathbf{i}$ & $\begin{array}{c}\mathbf{v} \\
(\mathbf{m} / \mathbf{s})\end{array}$ & $\begin{array}{c}\mathbf{v}^{*} \\
(\mathbf{m} / \mathbf{s})\end{array}$ & $\mathbf{f} \mathbf{i}$ & $\mathbf{f}(\mathbf{v i})$ & $\mathbf{F}(\mathbf{v i})$ \\
\hline 1 & $0-1$ & 0,5 & 26083,00 & 0,530455 & 0,530455 \\
\hline 2 & $1-2$ & 1,5 & 5903,00 & 0,120050 & 0,650505 \\
\hline 3 & $2-3$ & 2,5 & 3615,00 & 0,073519 & 0,724024 \\
\hline 4 & $3-4$ & 3,5 & 4703,00 & 0,095646 & 0,819670 \\
\hline 5 & $4-5$ & 4,5 & 2895,00 & 0,058879 & 0,878546 \\
\hline 6 & $5-6$ & 5,5 & 2825,00 & 0,057453 & 0,935999 \\
\hline 7 & $6-7$ & 6,5 & 1865,00 & 0,037929 & 0,973928 \\
\hline 8 & $7-8$ & 7,5 & 991,00 & 0,020154 & 0,994082 \\
\hline 9 & $8-9$ & 8,5 & 177,00 & 0,003600 & 0,997682 \\
\hline 10 & $9-10$ & 9,5 & 59,00 & 0,001200 & 0,998881 \\
\hline 11 & $10-11$ & 10,5 & 28,00 & 0,000569 & 0,999451 \\
\hline 12 & $11-12$ & 11,5 & 12,00 & 0,000244 & 0,999695 \\
\hline 13 & $12-13$ & 12,5 & 9,00 & 0,000183 & 0,999878 \\
\hline 14 & $13-14$ & 13,5 & 3,00 & 0,000061 & 0,999939 \\
\hline 15 & $14-15$ & 14,5 & 3,00 & 0,000061 & 1,000000 \\
\hline
\end{tabular}

Çizelgede ölçüm rüzgar hız verileri kullanılarak hesaplanan frekans dağılımlıları, Şekil 2'de gösterilmiştir. Şekilde, gerçek olasılık yoğunluğunun rüzgar hızı $0-1 \mathrm{~m} / \mathrm{s}$ aralığında en fazla olduğu, ve bu hız aralığında 26083 rüzgar esmenin gerçekleştiği görülmektedir. Rüzgar hızının artması ile olasılık yoğunluğunda azalma gerçekleşmektedir. $\mathrm{Bu}$ da kümülatif frekans dağılımına katkısı az olmaktadır. 


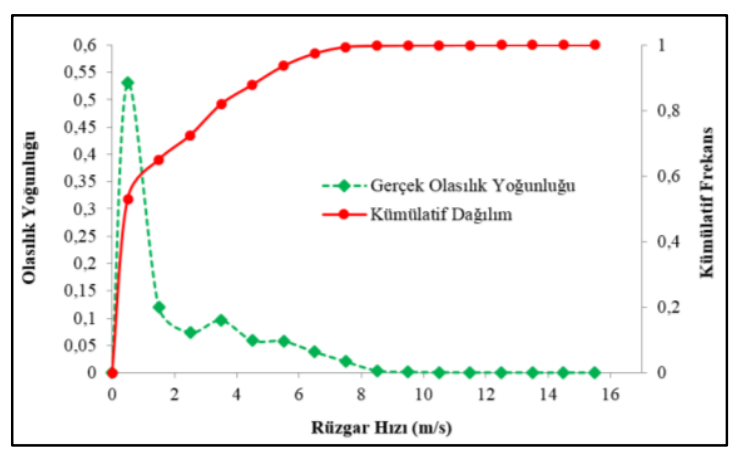

Şekil 2. Ölçülen rüzgar hızına göre gerçek ve kümülatif dağılımı

\section{WEIBULL DAĞILIMI}

Bir bölgenin rüzgar hız karakteristik (yön ve şiddet) değerinin bulunması için farklı dağılım yöntemleri kullanılmaktadır. $\mathrm{Bu}$ yöntemler arasında en çok tercih edilen yöntem Weibull dağılımıdır. Olasılık yoğunluğu ile tanımlanabilen Weibull dağılımı, Eşitlik 1 ve 2'de [15] f(v) rüzgar hızının olasılık fonksiyonu ve $\mathrm{F}(\mathrm{v})$ kümülatif dağılım fonksiyonu ile hesaplanmıştır.

$f(v)=\frac{k}{c}\left(\frac{v}{c}\right)^{k-1} \exp \left[-\left(\frac{v}{c}\right)^{k}\right]$

$F(v)=1-\exp \left[-\left(\frac{v}{c}\right)^{k}\right]$

$\mathrm{Bu}$ eşitliklerde, v rüzgar hızı, $\mathrm{k}$ boyutsuz şekil parametresi ve c ise ölçek parametresidir. Weilbull dağılımında şekil parametresi değerinin iki kabul edilmesi dağılıma Rayleigh olarak adlandırılmaktadır.

\section{WEIBULL PARAMETRELERININ BELIRLENMESI}

$\mathrm{Bu}$ çalışmada, Weibull rüzgar hızı dağılımı parametrelerini tahmin etmede literatürde en çok kullanılan üç yöntem sunulmuştur: Bunlar sırasıyla Grafik Yöntemi (Graphical Method_GM), En Yüksek Olabilirlik Yöntemi (The maximum likelihood method_MLM) ve Değiştirilmiş En
Yüksek Olabilirlik Yöntemi (The modixed maximum likelihood method_MMLM)'dir.

\subsection{Grafik Yöntemi (GM)}

Grafiksel yöntemin uygulanmasında, rüzgar hızı verilerinin kümülatif frekans dağılım formatında olması gerekmektedir. Bu nedenle, zaman serisi verileri öncelikle ayrıştırılmalıdır. En iyi uyan çizgi elle çizilebilir veya en küçük kareler regresyonu kullanılarak belirlenebilir. Eşitlik (2)'den Eşitlik (3) elde edilmektedir [16,17].

$\ln [-\ln (1-\mathrm{F}(\mathrm{v}))]=\mathrm{k} \ln \mathrm{v}-\mathrm{k} \ln \mathrm{c}$

$\mathrm{X}_{\mathrm{i}}$ (lnv) ve $\mathrm{Y}_{\mathrm{i}}(\ln [-\ln (1-\mathrm{F}(\mathrm{v}))])$ düzeni grafiğine aktarılmış (Şekil 3) ve bir lineer eşitlikten $\mathrm{y}=\mathrm{Ax}$ + B'den; A = k, B = -klnc katsayılarından k ve c parametreleri sirasiyla, 0,8807 ve 1,2720 olarak hesaplanmıştır.

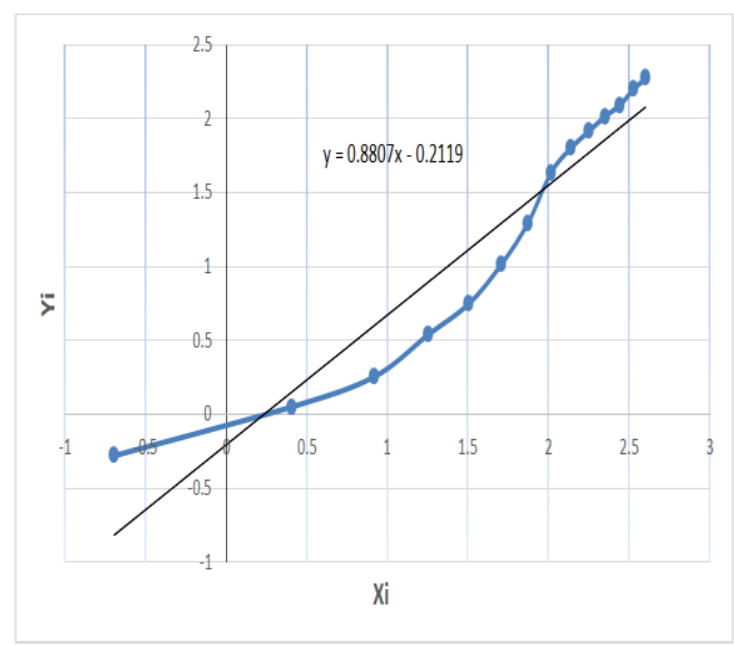

Şekil 3. Ölçümü yapılan gerçek rüzgar hızların $\mathrm{X}_{\mathrm{i}}$ ve $Y_{i}$ grafiğinde gösterimi

Elde edilen $\mathrm{k}$ ve $\mathrm{c}$ parametreleri kullanılarak Weibull olasılık dağılımı ile gerçek olasılık dağılımının karşılaştırılması Şekil 4'de gösterilmiştir. Şekilde 2-5 m/s hız değerleri arasında çok azda olsa farklılık olmasına rağmen genel olarak grafik yöntemi ile elde edilen Weilbull dağılımının gerçek veriler ile benzer trend gösterdiği görülmektedir. 


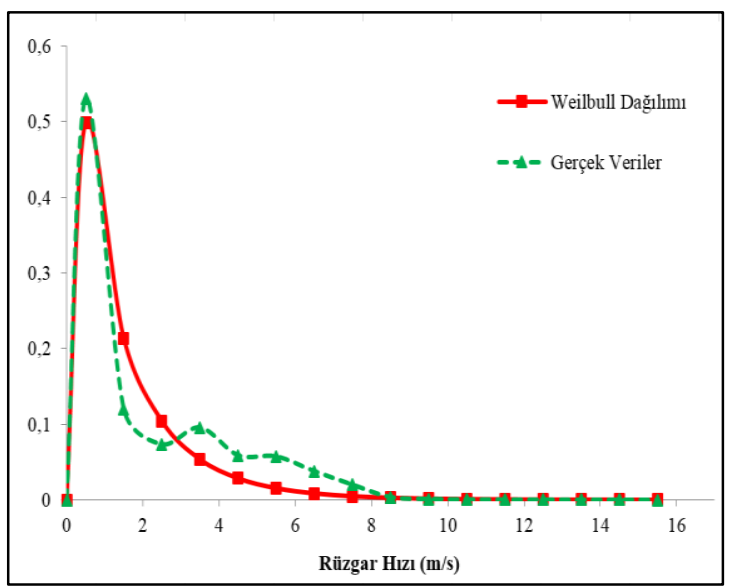

Şekil 4. Ölçülen gerçek rüzgar hızı veriler ile Weibull dağılımının gösterimi

\subsection{En Yüksek Olabilirlik Yöntemi (MLM)}

Weibull dağılımında şekil (k) parametresi ve ölçek parametresi (c) değerleri, Stevens ve Smulders tarafından önerilen En Yüksek Olabilirlik Yöntemi kullanılarak, rüzgar zaman serisi verilerine uygulanıp hesaplanmaktadır $[16,18]$. Şekil parametresi $(\mathrm{k})$ ve ölçek parametresi (c) aşağıdaki eşitlikte verilmiştir (Eşitlik 4,5).

$k=\left[\frac{\sum_{i=1}^{n} v_{i}^{k} \ln \left(v_{i}\right)}{\sum_{i=1}^{n} v_{i}^{k}}-\frac{\sum_{i=1}^{n} \ln \left(v_{i}\right)}{n}\right]^{-1}$

$c=\left(\frac{1}{n} \sum_{i=1}^{n} v_{i}^{k}\right)^{1 / k}$

$\mathrm{v}_{\mathrm{i}}$, i zaman adımındaki rüzgar hızıdır ve $\mathrm{n}$, sıfır olmayan rüzgar hızı veri noktalarının sayısıdır.

\subsection{Değiştirilmiş En Yüksek Olabilirlik Yöntemi (MMLM)}

Frekans dağılım fonksiyonunda rüzgar hızı verileri mevcutsa, değiştirilmiş en yüksek olabilirlik yöntemi düşünülebilir. İki Weibull parametresi Eşitlik (6) ve Eşitlik (7) ile hesaplanır [15,16]:

$\mathrm{k}=\left[\frac{\sum_{\mathrm{i}=1}^{\mathrm{n}} \mathrm{v}_{\mathrm{i}}^{\mathrm{k}} \ln \left(\mathrm{v}_{\mathrm{i}}\right) \mathrm{f}\left(\mathrm{v}_{\mathrm{i}}\right)}{\sum_{\mathrm{i}=1}^{\mathrm{n}} \mathrm{v}_{\mathrm{i}}^{\mathrm{k}} \mathrm{f}\left(\mathrm{v}_{\mathrm{i}}\right)}-\frac{\sum_{\mathrm{i}=1}^{\mathrm{n}} \ln \left(\mathrm{v}_{\mathrm{i}}\right) \mathrm{f}\left(\mathrm{v}_{\mathrm{i}}\right)}{\mathrm{f}(\mathrm{v} \geq 0)}\right]^{-1}$ $c=\left[\frac{1}{f(v \geq 0)} \sum_{i=1}^{n} v_{i}^{k} f\left(v_{i}\right)\right]^{1 / k}$

$\mathrm{V}_{\mathrm{i}}$, aralıktaki rüzgar hızı olup $\mathrm{n}$ ise toplam veri sayısıdır. $f\left(v_{i}\right)$ ve $f\left(v_{i} \geq 0\right)$ bölmelerinde değişen rüzgar hızı frekansı, sıfıra eşit veya sıfırdan fazla rüzgar hızı olasılığıdır.

\section{6. İSTATIKSEL ANALIZ}

Weibull dağılımlarının performansını değerlendirmek için belirlilik katsayısı $\left(\mathrm{R}^{2}\right)$ kriteri kullanılmıştır. $\mathrm{Bu}$ değer aşağıdaki formülden hesaplanmaktadır (Eşitlik 8).

$R^{2}=\frac{\sum_{i=1}^{N}\left(y_{i}-z_{i}\right)^{2}-\sum_{i=1}^{N}\left(y_{i}-x_{i}\right)^{2}}{\sum_{i=1}^{N}\left(y_{i}-z_{i}\right)^{2}}$

Eşitlikte; $y_{i}, \quad$ i. gerçek datayı, $x_{i}, \quad$ i. Weibull dağılımından tahmin edilen datayı, $z_{i}, \quad y_{i}^{\prime}$ lerin ortalama değerini ve $\mathrm{N}$ gözlem sayısıdır. Belirlilik katsayısı kriterinde, bir modelin, tahminin ölçüsü olarak 0 ve 1 arasında değişir ve elde edilen değerin 1'e yaklaşması modelin tahmin gücünün arttığını; 0'a yaklaşması ise modelin gücünün azaldığının göstergesidir [9].

\section{BULGULAR}

$\mathrm{Bu}$ bölümde, gerçek rüzgar hız değerleri ile Weibull dağılımında kullanılan, Grafik Yöntemi, En Yüksek Olabilirlik Yöntemi ve Değiştirilmiş En Yüksek Olabilirlik Yönteminden elde edilen aylık ve yıllık sonuçların karşılaştırılması yapılmıştır.

Şekil 5'de Olasılık Yoğunluk Fonksiyonları GM, MLM ve MMLM metotları ile karşılaştırılmıştır. Rüzgar Hızı, 0-1 aralığında, yaklaşık 0,53 olup, bölgenin rüzgar hız değeri artıkça olasılık yoğunluk fonksiyonunun azaldığı görülmektedir. Weilbull parametrelerinden GM, mevcut ölçülen rüzgar hızı değerlerine daha yakın değerlere ulaşmaktadır. Olasılık yoğunluk fonksiyonunda, MLM ve MMLM ise rüzgar hızına göre daha düşük sonuçlar vermiştir. 
Çizelge 6'da ölçümü yapılan aylık hız ortalamaları verilmiştir. Hızların yıllık ortalaması, 1,91 olup, ölçümü yapılan bölgenin hız ortalaması Haziran ayında yükselmeye başlayıp, Temmuz ayında en yüksek değere ulaşmakta, daha sonra tekrardan kademeli bir şekilde azalmaktadır. En düşük aylık h1z ortalaması $0,49 \mathrm{~m} / \mathrm{s}$ ile Kasım ayında gerçekleşmiştir. Yıllık ortalama hız değeri rüzgar yatırım sınıflandırması göz önüne alındığında [10] bu yerleşke için rüzgar potansiyelinin yeterli seviyede olmadığını göstermektedir.

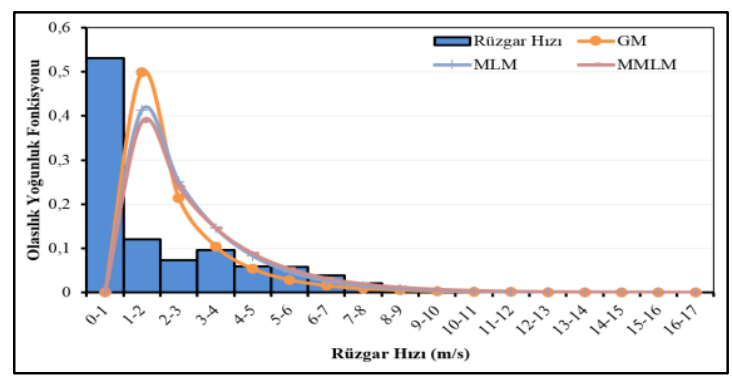

Şekil 5. Olasılık yoğunluk fonksiyonlarının GM, MLM ve MMLM ile kiyaslanması

Çizelge 6. Aylık ve yıllık ortalama hız değerleri

\begin{tabular}{|c|c|c|c|c|c|c|}
\hline Ocak & Şubat & Mart & Nisan & Mayıs & Haziran & Temmuz \\
\hline 0,87 & 1,47 & 2,15 & 2,01 & 2,13 & 2,92 & 3,17 \\
\hline A ğustos & Eylül & Ekim & Kasım & Aralık & Yıllık & \\
\hline 2,79 & 2,202 & 1,30 & 0,49 & 0,95 & 1,91 & \\
\hline
\end{tabular}

Literatürlerde, Weibull parametrelerini belirleme yöntemlerinden en uygun olanı belirlemede pek çok faklı İstatiksel analizler (Akaike informasyon kriteri (AIC), kök ortalama kare hata (RMSE), kikare $\left(\chi^{2}\right)$ ve belirlilik katsayısı $\left(\mathrm{R}^{2}\right)$ kriterleri vb.) yapılmaktadır. Bu çalışmada belirlilik katsayısı ile ölçümü yapılan verilere göre üç metotla hazırlanan parametrelerin analizleri gerçekleştirilmiştir. Osmaniye Korkut Ata Üniversitesi Mühendislik Fakültesi çatısından ölçülen verilere göre hesaplanan Weibull parametreleri ve $\mathrm{R}^{2}$ değerleri Çizelge 7'de verilmiştir. Çizelge 7'den anlaşılacağ 1 üzere GM, MLM ve MMLM yöntemleri uygulandığında yıllık $\mathrm{R}^{2}$ değerleri sırasıyla 0,9409 , 0,8617 ve 0,8509 dur. Bu ölçümden hesaplanan değerlere göre, GM y1llık değerler göz önüne alındığında diğer yöntemlerden daha iyi sonuç verdiği görülmüştür. Fakat aylık değerlere göre bakıldığında her ay için grafiksel yöntemin diğer yöntemlere kıyaslandığında daha iyi olduğu söylenemez. GM yönteminin Ocak, Kasım ve Aralık aylarında belirlilik katsayısı analizine göre diğer yöntemlerden daha düşük değere sahip olmaktadır. Genel olarak, Çizelgeye bakıldığı zaman GM bu ölçüm yılı için en iyi sonuca sahiptir.

Çizelge 7. GM, MLM ve MMLM için aylık ve yıllık k ve c parametreleri

\begin{tabular}{|l|c|c|c|c|c|c|c|c|c|}
\hline & \multicolumn{3}{|c}{ GM } & \multicolumn{3}{c|}{ MLM } & \multicolumn{3}{c|}{ MMLM } \\
\hline & $\mathbf{k}$ & $\mathbf{c}$ & $\mathbf{R}^{\mathbf{2}}$ & $\mathbf{k}$ & $\mathbf{c}$ & $\mathbf{R}^{\mathbf{2}}$ & $\mathbf{k}$ & $\mathbf{c}$ & $\mathbf{R}^{\mathbf{2}}$ \\
\hline Ocak & 0,6227 & 0,3911 & 0,8442 & 1,2837 & 1,0312 & 0,9644 & 1,2208 & 1,0780 & 0,9561 \\
\hline Şubat & 0,7813 & 0,9033 & 0,9827 & 1,1243 & 0,3213 & 0,9513 & 1,0994 & 1,6232 & 0,9208 \\
\hline Mart & 0,7659 & 1,3779 & 0,9717 & 1,0474 & 2,2010 & 0,8796 & 1,0014 & 2,1918 & 0,8940 \\
\hline Nisan & 0,8606 & 1,3103 & 0,9257 & 1,0904 & 2,0467 & 0,8265 & 0,0493 & 2,1165 & 0,8347 \\
\hline Mayıs & 0,7691 & 1,4017 & 0,9311 & 1,1481 & 2,2840 & 0,7835 & 1,0769 & 2,2387 & 0,8214 \\
\hline Haziran & 0,9911 & 2,0868 & 0,7556 & 1,2295 & 3,0807 & 0,7161 & 1,1726 & 3,0995 & 0,7515 \\
\hline Temmuz & 1,0415 & 2,3573 & 0,6018 & 1,3499 & 3,5068 & 0,5935 & 1,2541 & 3,4102 & 0,6485 \\
\hline Ağustos & 0,9179 & 1,9219 & 0,7922 & 1,1381 & 2,9674 & 0,6640 & 1,0610 & 2,2921 & 0,7151 \\
\hline Eylül & 0,9247 & 1,3630 & 0,8612 & 1,1328 & 2,1151 & 0,7497 & 1,0741 & 2,1803 & 0,7728 \\
\hline Ekim & 0,7468 & 0,7646 & 0,9517 & 1,0766 & 0,7358 & 0,9223 & 1,0972 & 1,4791 & 0,8804 \\
\hline Kasım & 0,6396 & 0,2456 & 0,7229 & 1,4333 & 0,5993 & 0,986 & 1,3641 & 0,8537 & 0,9650 \\
\hline Aralık & 0,5963 & 0,4364 & 0,8285 & 1,1532 & 1,1066 & 0,9479 & 1,1189 & 1,1599 & 0,9257 \\
\hline Yıllık & $\mathbf{0 , 8 8 0 7}$ & $\mathbf{1 , 2 7 2 0}$ & $\mathbf{0 , 9 4 0 9}$ & $\mathbf{1 , 0 4 6 9}$ & $\mathbf{1 , 8 4 6 4}$ & $\mathbf{0 , 8 6 1 7}$ & $\mathbf{1 , 0 1 5 6}$ & $\mathbf{2 , 0 1 1 6}$ & $\mathbf{0 , 8 5 0 9}$ \\
\hline
\end{tabular}




\section{SONUÇLAR}

Bu çalışmada, gerçek ölçüm verilerine göre rüzgar hızının aylık yıllık ortalama değerleri hesaplanmıştır. Hız değerleri ile ölçüm yapılan bölgenin olasılık yoğunluk fonksiyonu elde edilmiştir. Bir sonraki adımda ise ölçüm değerleri üç farklı metot ile Weilbull parametreleri hesaplanmıştır. Hesaplanan parametreler için belirlilik katsayısı ile istatiksel analiz yapılmıştır. En yüksek $\mathrm{R}^{2}$ değeri 0,9827 için Şubat ayında GM iken, en düşük $\mathrm{R}^{2}$ değeri 0,5935 için Temmuz ayında MLM yönteminde olduğu görülmüştür. 2013 yıllık verileri göz önüne alındığında, Weilbull dağılımında GM yönteminin daha uygun olduğu sonucuna varılmıştır. Bu çalışma ile Osmaniye Korkut Ata Üniversitesi, Mühendislik Fakültesi çatısında ölçümü yapılan rüzgar hızı ile kampüsün rüzgar enerjisi tahmini elde edilmiştir.

\section{KAYNAKLAR}

1. Şenel, M., Koç, E., 2015. Dünyada ve Türkiye'de Rüzgar Enerjisi Durumu-Genel Değerlendirme. Mühendis ve Makina, 56(663), 46-56.

2. Özdamar, A., 2001. Farklı Anma Güçlü Rüzgar Türbinlerinin Çeşitli Kriterlere Göre Karşılaştırılması, Pamukkale Üniversitesi, Mühendislik Bilimleri Dergisi, 7(1), 17-27.

3. Özşahin, E., Kaymaz, Ç., 2014. Rüzgar Enerji Santrallerinin (Res) Kuruluş Yeri Seçiminin Cbs ile Analizi: Hatay Örneği . TÜBAV Bilim Dergisi, 6(2), 1-18.

4. Bilgili, M., Şahin, B., Şimşek, E., 2010. Türkiye'nin Güney, Güneybat1 ve Bat1 Bölgelerindeki Rüzgar Enerjisi Potansiyeli, Isı Bilimi ve Tekniği Dergisi, 30(1), 01-12.

5. Yıldırım, U., Gazibey, Y., Güngör A., 2016. Niğde İli Rüzgar Enerjisi Potansiyeli, Niğde Ömer Halisdemir Üniversitesi Mühendislik Bilimleri Dergisi, 1(1), 37-47.

6. Gülersoy, T., Çetin, N., 2010. Menemen Bölgesinde Rüzgar Türbinleri için Rayleigh ve Weibull Dağılımlarının Kullanılması, Politeknik Dergisi, 13(3), 209-213.

7. Dikmen, E., Örgen, F., 2018. Ağlasun Bölgesi için Rüzgar Hızı Tahmini ve En Uygun Türbin
Tespiti, Niğde Ömer Halisdemir Üniversitesi Mühendislik Bilimleri Dergisi, 7(2), 871-879.

8. Akkaya, M., Gültekin, A., Sabanc1, K., Balcı, S., Sağlam, H., 2020. Analysis and Applicability of Mersin Region Wind Speed Data with Artificial Neural Networks, Nevşehir Bilim ve Teknoloji Dergisi, 9(1), 39-51.

9. Kurban, M., Hocaoğlu, F., Kantar, Y., 2007. Rüzgar Enerjisi Potansiyelinin Tahmininde Kullanılan İki Farklı İstatistiksel Dağılımın Karşılaştırmalı Analizi, Pamukkale Üniversitesi, Mühendislik Bilimleri Dergisi, 13(1), 103-109.

10.T.C. Enerji ve Tabii Kaynaklar Bakanlığı, Rüzgar Bilgi Merkezi,

https://enerji.gov.tr/bilgi-merkezi-enerji-ruzgar.

11. Türkiye Rüzgar Enerjisi Birliği (TÜREB), Türkiye Rüzgar Enerjisi İstatistik Raporu, Temmuz 2020. https://tureb.com.tr/eng/lib/uploads/0fcf336c19 d4b950.pdf, Erişim Tarihi: 20.02.2021.

12. Türkiye Bilimler Akademisi, TÜBA-Rüzgar Enerjisi Teknolojileri Raporu, TÜBA Raporları No: 28, Ankara-2019.

13. Rüzgar Gücü İzleme ve Tahmin Merkezi, http://www.ritm.gov.tr/root/index.php, Erişim Tarihi: 23.02.2021.

14. Türkiye Rüzgar Enerjisi Potansiyeli, https://repa.enerji.gov.tr/REPA/, Erişim Tarihi: 21.02.2021.

15. Chang, TP., 2011. Performance Comparison of Six Numerical Methods in Estimating Weibull Parameters for Wind Energy Application, Applied Energy, 88, 272-282.

16. Seguro, J.V., Lambert, T.W., 2000. Modern Estimation of the Parameters of the Weibull Wind Speed Distribution for Wind Energy Analysis. Journal of Wind Engineering and Industrial Aerodynamics, 85, 75-84.

17. Yaniktepe, B., Koroglu, T., Savrun, M.M., 2013. Investigation of Wind Characteristics and Wind Energy Potential in Osmaniye, Turkey, Renewable and Sustainable Energy Reviews, 21, 703-711.

18. Stevens, M.J., Smulders, P.T., 1979. The Estimation of the Parameters of the Weibull Wind Speed Distribution for Wind Energy Utilization Purposes, Wind Eng., 3(2), 132-145. 